\title{
Pattern of ocular morbidity in pediatrics age group in a tertiary centre in western Nepal
}

\author{
Tuladhar S1, Gurung J'2, Poudel B ${ }^{3}$, Subedi N4 \\ 'AssociateProfessor, Department of ophthalmology, Gandaki Medical College \\ 2Lecturer, Department of ophthalmology, Gandaki Medical College \\ ${ }^{3}$ Ophthalmic assistant, Department of ophthalmology, Gandaki Medical College \\ ${ }^{4}$ Lecturer, Department of pediatrics, Gandaki Medical College
}

\section{Keywords}

Amblyopia, childhood blindness, visual acuity

\section{Corresponding author}

Dr. Sarita Tuladhar Associate Professor, Department of ophthalmology, Gandaki Medical College

Gandaki Medical College \& Teaching Hospital, Pokhara , Nepal

Email: drtuladharsarita@yahoo.com

\section{ABSTRACT}

Introduction: Ocular morbidities are importantbecause of their impact on child's development,education and future work. Ocular morbidities in children may not be diagnosed and treated in time due to inability to express their problems which leads to amblyopia by the time they can express it. This study was conducted with an objective to determine the pattern of ocular morbidity in children less than and equal to 14 years of age presenting in the Outpatient Department (OPD) of Gandaki Medical College, Pokhara.

Materials/ Methods: This is a cross sectional observational study where we reviewed the profile of all of all patients of age group equal to or less than 14 years entering eye OPD from September 2016 to September 2018 for eye examination.

Result: A total of 1471 patients presented to eye department of GMC. The mean age of the patient was $8.25 \pm 4.24$ years among which $57.8 \%$ were males and $42.2 \%$ were females. Maximum number of the patients were in age group 11 to 14 years (38.1\%) while minimum number of the patients were in the age group $<1$ year(10.6\%).Conjunctival disorders (23.9\%) was the most common ocular morbidity followed by refractive error in (18.2\%), miscellaneous conditions (10.4\%), eyelid diseases (8.6\%), lacrimal system diseases (7.8\%).

Conclusion: Thestudy gives a picture and pattern of ocular diseases in pediatrics age group which not only helps in early diagnosis and treatment of ocular diseases but also in decreasing the magnitude of childhood blindness and amblyopia.

\section{INTRODUCTION}

Ocular morbidities are importantbecause of their impact on child's development,education, future work. Childhood ocular morbidities and if undetected, may result in severe ocular disabilities or even blindness.Childhood blindness is one of the major causes of preventable blindness. According to WHO, there are estimated 1.4 million childhood blindness worldwide of which two third live in the developing 6 countries like Nepal.1

The major causes of childhood blindness in developing countries like Nepal are vitamin A deficiency, measles, trachoma, refractive errors, amblyopia. Childhood blindness is one of the component of WHO's vision 2020 programme to control blindness. After eradication of trachoma recently from Nepal in 2018 (WHO), challenges to control childhood blindness and amblyopia is still present.

Ocular morbidities in children may not be diagnosed and treated in time due to inability to express their problems which leads to amblyopia by the time they can express it. Data onocular morbidity in children isessential for 
planning and evaluation of preventive andcurative services for children. Few hospital based studies are available on childhood ocular morbidities in Western Nepal.2

Information obtained from our study might be useful in improving the existing primaryeye care facilities consequently reducing the prevalence of childhood blindness and severe visual impairment.

Gandaki Medical College (GMC) is a tertiary centre in Western Nepal. A number of pediatrics patients come to the eye department of this college. So we performed the study to determine the pattern of ocular morbidities in children less than and equal to 14 years age presenting in the Outpatient Department of GMC. This type of study helps not only in early diagnosis and treatment of ocular diseases but also in decreasing the magnitude of childhood blindness and amblyopia.

\section{METHODS}

This is a cross sectional observational study where we reviewed the profile of all the patients of the age group equal to or less than 14 years entering eye OPD from September 2016 to September 2018 for eye examination. Data on age at presentation, sex and diagnosis were collected from OPD records. Patients were grouped into four groups ( $<1$ year, 1-5 years, 6-10 years and 11-14 years).

Data on age at presentation, sex and diagnosis were collected from OPD records. Patients were grouped into four age groups ( $<1$ years, 1 to 5 years, 6 to 10 years and 11 to 14 years).

In all the patients, visual acuity was taken and refraction performed routinely. Orthoptics evaluation and cycloplegic refraction were performed when needed.Anterior segment examination was done with torch and slit lamp. Posterior segment examination was performed after dilating the pupil using direct and indirect ophthalmoscope. The data were recorded and analyzed using SPSS statistics programme version 11.6.

\section{RESULT}

A total of 1471 patients presented to eye department of GMC. The mean age of the patient was $8.25 \pm 4.24$ years among which $57.8 \%$ were male and $42.2 \%$ were female.
Maximum number of the patients were in age group 11 to 14 years $(38.1 \%)$ while minimum number of the patients were in age group $<1$ year. $(10.6 \%)$. Details of the age and sex distribution is shown in figure 1.

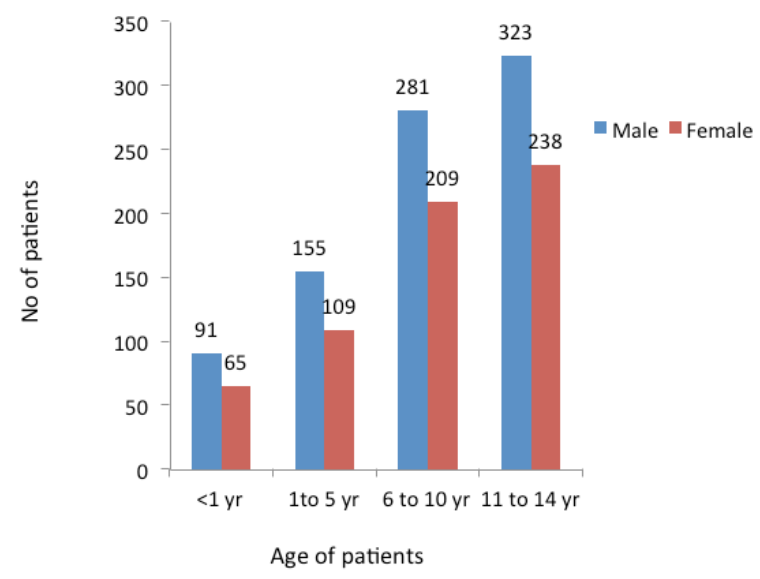

Figure 1: Distribution of patients in different age group

Regarding presenting complaints, blurring of vision was the most common seen in $20.3 \%$, followed by itching (13.3\%), redness $(11.6 \%)$. Details of common symptoms are shown in figure 2 .

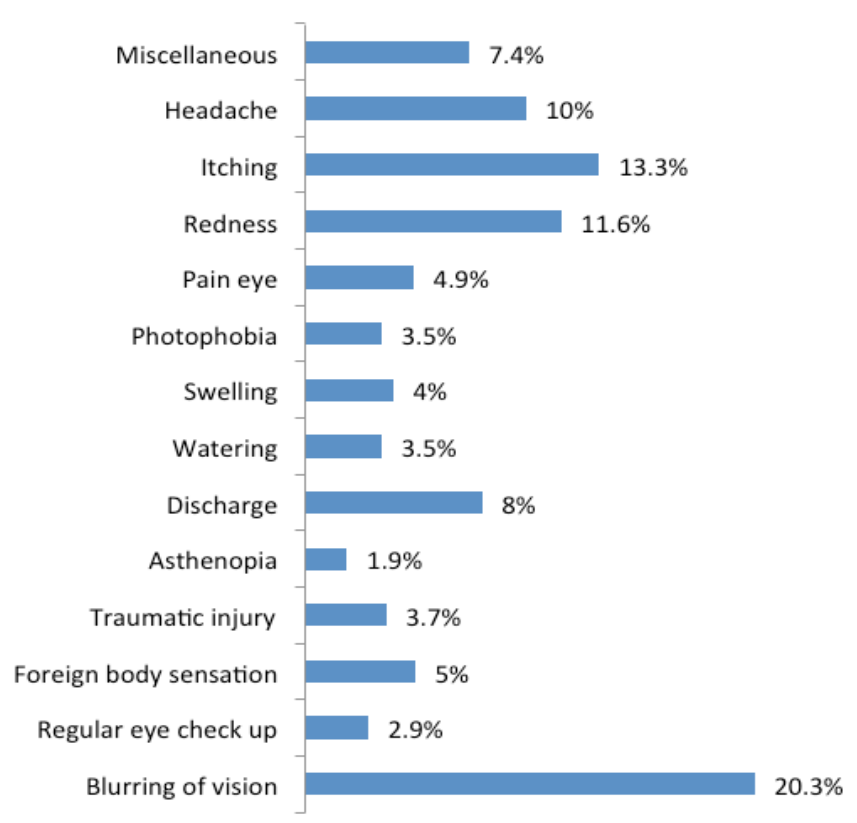

Figure 2: Chief complaints of patients

Miscellaneous symptoms include deviation of eyeball, drooping of eyelids, double vision, and forward protrusion of eyeball. In our study, majority of the patients had conjunctival disorders (23.9\%) followed by refractive error (18.2\%), normal (12\%), miscellaneous conditions $(10.4 \%)$, eyelid diseases (8.6\%), lacrimal system diseases (7.8\%). Details of ocular morbidities are shown in Table 1. 
Table 1: Distribution of ocular morbidity

\begin{tabular}{|c|c|c|c|c|c|}
\hline \multirow{2}{*}{ Morbidities } & \multicolumn{4}{|c|}{ Age group } & \multirow{2}{*}{ Total } \\
\hline & $<1 \mathrm{yr}$ & $1-5 \mathrm{yr}$ & $6-10 \mathrm{yr}$ & $11-14$ & \\
\hline Refractive error & 0 & $\begin{array}{c}10 \\
(0.7 \%)\end{array}$ & $\begin{array}{c}106 \\
(7.2 \%)\end{array}$ & $\begin{array}{c}151 \\
(10.3 \%)\end{array}$ & $\begin{array}{c}267 \\
(18.2 \%)\end{array}$ \\
\hline Orbit & $2(0.1 \%)$ & $\begin{array}{c}5 \\
(0.3 \%)\end{array}$ & $\begin{array}{c}8 \\
(0.5 \%)\end{array}$ & $\begin{array}{c}10 \\
(0.7 \%)\end{array}$ & $\begin{array}{c}25 \\
(1.7 \%)\end{array}$ \\
\hline Squint & $3(0.2 \%)$ & $\begin{array}{c}7 \\
(0.5 \%)\end{array}$ & $\begin{array}{c}10 \\
(0.7 \%)\end{array}$ & $\begin{array}{c}16 \\
(1 \%)\end{array}$ & $\begin{array}{c}36 \\
(2.4 \%)\end{array}$ \\
\hline Amblyopia & 0 & 0 & $\begin{array}{c}8 \\
(0.6 \%)\end{array}$ & $\begin{array}{c}21 \\
(1.4 \%)\end{array}$ & $\begin{array}{c}29 \\
(2 \%)\end{array}$ \\
\hline Lid & $1(0.1 \%)$ & $\begin{array}{c}30 \\
(2 \%)\end{array}$ & $\begin{array}{c}54 \\
(3.6 \%)\end{array}$ & $\begin{array}{c}42 \\
(2.9 \%)\end{array}$ & $\begin{array}{c}127 \\
(8.6 \%)\end{array}$ \\
\hline $\begin{array}{l}\text { Lacrimal } \\
\text { drainage system }\end{array}$ & $73(5 \%)$ & $\begin{array}{c}33 \\
(2.2 \%)\end{array}$ & $\begin{array}{c}8 \\
(0.5 \%)\end{array}$ & $\begin{array}{c}1 \\
(0.1 \%)\end{array}$ & $\begin{array}{c}115 \\
(7.8 \%)\end{array}$ \\
\hline Conjunctiva & $\begin{array}{c}51 \\
(3.5 \%)\end{array}$ & $\begin{array}{c}84 \\
(5.7 \%)\end{array}$ & $\begin{array}{c}87 \\
(5.9 \%)\end{array}$ & $\begin{array}{c}130 \\
(8.8 \%)\end{array}$ & $\begin{array}{c}352 \\
(23.9 \%)\end{array}$ \\
\hline Cornea and sclera & 0 & $\begin{array}{c}21 \\
(1.5 \%)\end{array}$ & $\begin{array}{c}24 \\
(1.6 \%)\end{array}$ & $\begin{array}{c}19 \\
(1.3 \%)\end{array}$ & $\begin{array}{c}64 \\
(4.4 \%)\end{array}$ \\
\hline Lens & 0 & $\begin{array}{c}8( \\
0.5 \%)\end{array}$ & $\begin{array}{c}9 \\
(0.6 \%)\end{array}$ & $\begin{array}{c}4 \\
(0.3 \%)\end{array}$ & $\begin{array}{c}21 \\
(1.4 \%)\end{array}$ \\
\hline Uvea & 0 & $\begin{array}{c}1 \\
(0.1 \%)\end{array}$ & $\begin{array}{c}11 \\
(0.7 \%)\end{array}$ & $\begin{array}{c}14 \\
(1 \%)\end{array}$ & $\begin{array}{c}26 \\
(1.8 \%)\end{array}$ \\
\hline Vitreous and retina & 0 & $\begin{array}{c}1 \\
(0.1 \%)\end{array}$ & $\begin{array}{c}6 \\
(0.4 \%)\end{array}$ & $\begin{array}{c}7( \\
0.5 \%)\end{array}$ & $\begin{array}{c}14 \\
(1 \%)\end{array}$ \\
\hline $\begin{array}{l}\text { Optic nerve/ } \\
\text { neurophthalmlolgy }\end{array}$ & 0 & $\begin{array}{c}1 \\
(0.1 \%)\end{array}$ & $\begin{array}{c}13 \\
(0.9 \%)\end{array}$ & $\begin{array}{c}5 \\
(0.3 \%)\end{array}$ & $\begin{array}{c}19 \\
(1.3 \%)\end{array}$ \\
\hline Ocular trauma & $\begin{array}{c}3 \\
(0.2 \%)\end{array}$ & $\begin{array}{c}15 \\
(1 \%)\end{array}$ & $\begin{array}{c}22 \\
(1.5 \%)\end{array}$ & $\begin{array}{c}6 \\
(0.4 \% 0\end{array}$ & $\begin{array}{c}46 \\
(3.1 \%)\end{array}$ \\
\hline Normal & $\begin{array}{c}17 \\
(1.2 \%)\end{array}$ & $\begin{array}{c}34 \\
(2.3 \%)\end{array}$ & $\begin{array}{c}61 \\
(4.1 \%)\end{array}$ & $\begin{array}{c}65 \\
(4.4 \%)\end{array}$ & $\begin{array}{c}177 \\
(12 \%)\end{array}$ \\
\hline Miscellaneous** & $\begin{array}{c}5 \\
(0.3 \%)\end{array}$ & $\begin{array}{c}15 \\
(1 \%)\end{array}$ & $\begin{array}{c}64 \\
(4.4 \%)\end{array}$ & $\begin{array}{c}69 \\
(4.7 \%)\end{array}$ & $\begin{array}{c}153 \\
(10.4 \%)\end{array}$ \\
\hline Total & $\begin{array}{c}155 \\
(10.6 \%)\end{array}$ & $\begin{array}{c}265 \\
(18 \%)\end{array}$ & $\begin{array}{c}490( \\
33.3 \%)\end{array}$ & $\begin{array}{c}560 \\
(38.1 \%)\end{array}$ & $\begin{array}{c}1471 \\
(100 \%)\end{array}$ \\
\hline
\end{tabular}

* Miscellaneous: staphyloma, glaucoma, optic atrophy, coloboma, microcornia, retinoblastoma.

Among the conjunctival disorders, 91.5\% patients had conjunctivitis of which infective conjunctivitis was seen in $46.6 \%$ and allergic conjunctivitis was seen in $44.9 \%$ which is shown in table 2. Other conjunctival diseases include subconjunctival haemorrhage,conjunctival melanosis, cysts, papillomas. Conjunctivitis was more common in age group 11 to 14 years (8.8\%).

Refractive error was more common in age group 11 to 14 years $(10.3 \%)$ followed by six to 10 years $(7.2 \%)$ and one to five years $(0.7 \%)$. In age group $<1$ year, lacrimal system disease $(5 \%)$ was the most common disease followed by conjunctival disease (3.5\%). Congenital nasolacrimal duct obstruction with dacryocystitis was the most common lacrimal system disease. In age group one to five years, conjunctival disease was the most common disease (5.7\%) followed by normal patients $\quad(2.3 \%)$, lacrimal system disease (2.2\%). In age group six to 10 years, refractive error $(7.2 \%)$ was the most common ocular morbidity followed by miscellaneous conditions (4.4\%), eyelid diseases (3.6\%). In age group 11 to 14 years, refractive error $(10.3 \%)$ was the common morbidity followed by conjunctival disorders (8.8\%).

Amblyopia was seen in $2 \%$ of patients. Though less, diseases of lens $(1.4 \%)$, uvea $(1.8 \%)$, retina $(1.8 \%)$, and opticnerve $(1.3 \%)$ were also seen.3.1\% of the patients had ocular injuries and squint in $2.4 \%$ patients.

Table 2: Types of conjunctivitis

\begin{tabular}{ccc}
\hline Types of conjunctivitis & No. of patients & $\%$ \\
Infective & 164 & 46.6 \\
Allergic & 158 & 44.9 \\
Others & 30 & 8.5 \\
Total & 352 & 100 \\
\hline
\end{tabular}

\section{DISCUSSION}

In our study $57.8 \%$ were male and $42.2 \%$ were female. Similar results showing male preponderance was seen in studies byRai Salma KC et al, ${ }^{2}$ Sahoo JR et al, ${ }^{3}$ Sethi $\mathrm{S}$ et al, ${ }^{4}$ Ava $\mathrm{H}$ et al. ${ }^{5}$ This may be due to gender bias in health care seeking behavior in our community.

In our study, maximum number of the patients was in age group 11 to 14 years (38.1\%). Similar findings were seen in other studies by Rai Salma KC,2 Sahoo et al3, Gupta et al6. But other studies showed more patients in age group two to five years.5,7 More patients in older age group may be due to better communication skills and early expressions of their problems with the parents.

Blurred vision was the most common symptom followed by itching in our study which was comparable to study by Sahoo et $\mathrm{al}^{3}$ in India. But studies by Salma et al2shown watering was the most common symptom followed by blurring of vision. Blurring of vision was the most common symptom can be explained by the fact that it is more alarming for child and his family leading to prompt health seeking behavior.

In our study, majority of the patients had conjunctival disorders (23.9\%) followed by refractive error in (18.2\%), normal (12\%) miscellaneous conditions (10.4\%). A number of patients coming to eye OPD for examination were referral patients from pediatrics department resulting in a large number of normal patients in our 
study. Similar results showing more conjunctival diseases was seen in other studies by Salmaet $\mathrm{al}^{2}$ in Nepal, Gupta et $\mathrm{al}^{6}$ in India and Sadia Sethi et $\mathrm{al}^{8}$ in Pakistan. Whereas other studies showed more refractive errors. ${ }^{3,9}$ Less refractive errors compared to other studies can be due to the fact that a large number of the patients were referral patients from Pediatrics Department. Also majority of our patients were from urban areas going to school. Refractive errors are early diagnosed among school going children.

Among the conjunctival disorders, $91.5 \%$ patients had conjunctivitis of which infective conjunctivitis was seen in $46.6 \%$ and allergic conjunctivitis was seen in $44.9 \%$. But other studies showed more allergic conjunctivitis than infective. ${ }^{2,3,9}$ In our study, refractive error was most common in age group 11 to 14 years followed by six to 10 years which was similar to other studies.2,3

Eyelid disorders comprising mostly of chalazion, hordeolum, blepharitis was seen in $8.6 \%$ of the patients but in other studies there was slight variation in result.2,6,9 Poor eye hygiene of the children is responsible for eyelid disorders. Ocular trauma was seen in $3.8 \%$ of the patients. Foreign bodies, subconjunctival hemorrhage, eyelid lacerations were the main causes of the ocular trauma. But other studies showed higher numbers of ocular trauma cases. $^{3,6}$ The frequency of ocular trauma in children is also high worldwide due to unsupervised play and use of dangerous objects by children.

Lacrimal system disease was seen in $7.8 \%$ of the patients. Congenital dacryocystitis due to nasolacrimal duct obstruction was responsible for lacrimal system diseases in children. Other studies showed slightly higher rate of dacryocystitis. ${ }^{2,6,9}$ Our studies showed a large number of normal patients too (12\%). This can be explained by the fact that our hospital is a tertiary centre where a number of patients coming to eye department were referred patients from pediatrics department.

\section{CONCLUSION}

Our study showed that conjunctival disorders was the most common ocular morbidity followed by refractive error, eyelid diseases, lacrimal system diseases.

The study gives a picture and pattern of ocular diseases in pediatrics age group which not only helps in early diagnosis and treatment of ocular diseases but also helps in decreasing the magnitude of childhood blindness and amblyopia by providing health education and counseling

\section{REFERENCES}

1. World Health Organization: Program for the Prevention of Blindness and Deafness, and International Agency for Prevention of Blindness. Geneva: WHO; 2000. Contract No.: (WHO/PBL/00.77)

2. Rai Salma KC, Hari T, Malla BA, Kabindra B. Clinical profile of pediatric ocular morbidity in a Tertiary Eye Care Centre in Western Region of Nepal. Ann Pediatr Child Health. 2015;3(5):1070.

3. Sahoo JR, Jena D, Karmee N, Tripathy RM, Sahu PP. Prevalence of ocular morbidities among paediatric patients attending Ophthalmology OPD in MKCG Medical College Hospital, Berhampur, Odisha, India. Int J Adv Med. 2018 Apr;5(2):409-13.

4. Sethi S, Sethi MJ, Iqbal R, Khan T. Pattern of common eye diseases in children attending outpatient eye department, Khyber Teaching hospital, Peshawar. J Med Sci. 2008;16(2): 99-101.

5. Ava H, Hussain AHME, Ferdausi N, Akand AR. Profile of pediatric ocular morbidity in the In-Patient Department of an Apex Public Hospital. Austin J Clin Ophthalmol. 2014;1(6):1031.

6. Gupta P, Gupta V.Ocular morbidities in pediatric outpatient population at a tertiary care ophthalmic centre: A descriptive study. Int J Contemp Pediatr. 2018 Jul;5(4):1195-8.

7. Khan I A, Qamruddin M2.Assessment of Ocular Conditions among Pediatric Patients. International Journal of Contemporary Medical Research. 2017;4(1).

8. Sadia Sethi, Mohammad Junaid Sethi, Nasir Saeed, Naimatullah Khan Kundi. Pattern of common eye diseases in children attending Outpatient Eye Department Khyber Teaching Hospital. Pak J Ophthalmol. 2008;24(4).

9. Biswas J, Saha I, Das D, Bandyopadhyay S, Ray B, Biswas G. Ocular morbidity among children at a Tertiary Eye care Hospital in Kolkata, West Bengal. Indian J Public Health. 2012;56:293-6. 